\title{
OPTIMIZING THE COOLING SYSTEM OF THE SUEZ POWER PLANT TO AVOID THE MUTUAL EFFECT OF THE ATTAKA AND SUEZ PLANTS
}

\author{
Entesar A . S. EL-Ghorab1, Ahmed M. EL-Belasy2 and M. Bahgat3
}

1Assoc. Prof., Hydraulics Research Institute, National Water Research Centre, Egypt

2Ditto

3Researcher, Hydraulics Research Institute, National Water Research Centre, Egypt

\begin{abstract}
This research aims at investigating the optimum location of the intake and outfall of the cooling system of the Suez Power Plant. The Plant is planed to be built along the Suez Gulf. There is an existing power plant (Attaka Plant) at about $5 \mathrm{~km}$ west of the proposed Suez Plant. Hydrothermal numerical modeling was carried out. This model was developed to study the recirculation of the effluents at the intake of the Suez Plant and the distribution of the water temperature at its vicinity. The model is calibrated with the measured data. The results showed that when the Suez and Attaka Plants are in operation, the thermal plumes of both plants merge under specific conditions of wind direction and tides. This results in plume concentration between the two plants, which makes it difficult to locate the intake of the cooling system of Suez Power Plant. Different model scenarios were tested to optimize the cooling system of Suez Power Plant to avoid the recirculation of effluents. Based on the scenarios results, one option was selected to achieve the optimum design of the plant cooling system to determine the shape and location of the intake and outfall of the plant from both recirculation and marine life point of view.
\end{abstract}

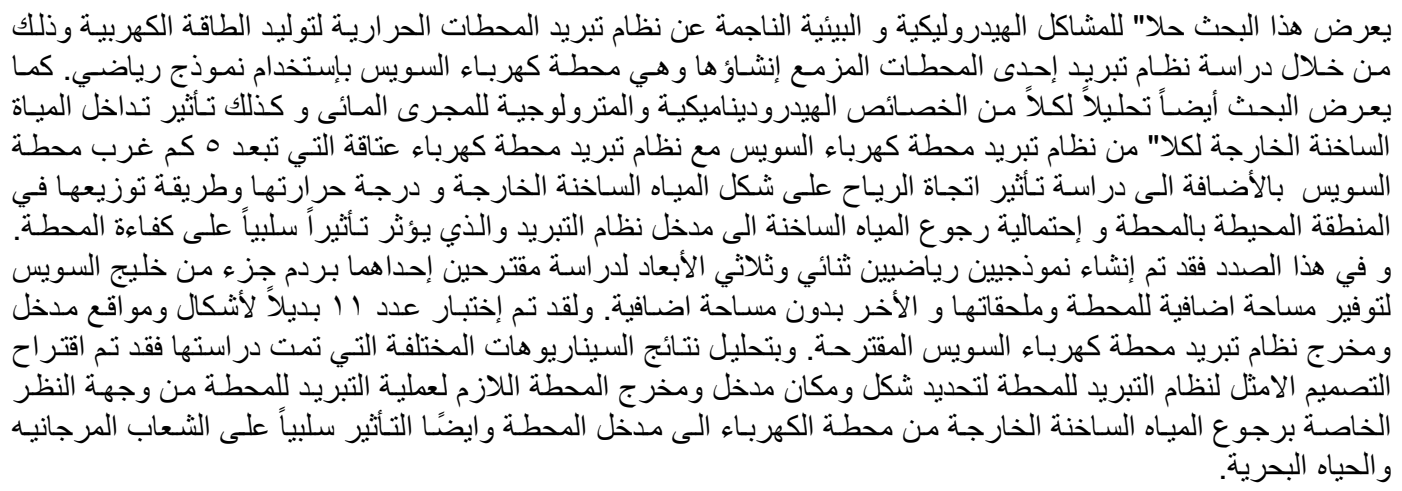

Keywords: Recirculation, Thermal Plume, Tides, Hydrodynamic Model 


\section{INTROUDUCTION}

Pollutants discharging into marine and coastal waters can be classified based on their origin as natural and anthropogenic. Anthropogenic originated pollutions are mainly discharged from inland as domestic and industrial wastewaters, either via marine outfalls or rivers. A marine outfall is a mean for discharging industrial wastewater, storm runoff or sewage out to undersea disposal point.

Adverse effects of thermal discharges on marine environment (i.e. coral reefs, beaches, coasts and estuaries) have been reported in previous works $[1 ; 2 ; 3 ; 4]$.

Regarding thermal discharges environmental and coastal economic effects, developing alternative methods to predict dilution thermal discharges in marine environments seems to be very important.

The design and construction of marine cooling system of power plants require economic and human efforts. It is therefore, necessary to assure the perfect performance of the cooling system, either by using physical or numerical models. Physical modeling usually is a time consuming task and is limited to technical constraints. On the other hand, numerical modeling allows simulation of a great number of scenarios and can be used more effectively for the optimal design. These models, however, need to be verified using measurements either in the field or in the laboratory [5].

Heated water discharged from power plants can increase the ambient water temperature. This process can negatively affect the coastal environment. According to the environmental standards, the maximum allowable increase in ambient temperature due to the thermal discharges shall not exceed $2^{\circ} \mathrm{C}[6]$.

In the immediate vicinity of the discharge ("near field"), the jet trajectory and mixing are mainly governed by the source momentum flux, buoyancy flux, outfall geometry, and ambient velocity and stratification as presented in Figure1 [7]. The influence of the source characteristics decreases further away from the discharge point. The region where the effluent is passively transported by ambient currents and further diluted by ambient turbulent diffusion is referred to as the "far field". In the near-far field transition ("intermediate field"), the dynamics depends on both the jet momentum and buoyancy, and the ambient flow. To correctly simulate the dominant physical processes in this region, the dynamic near field effects of the discharge and the corresponding volume and mass fluxes need to be properly modeled in the far field model.

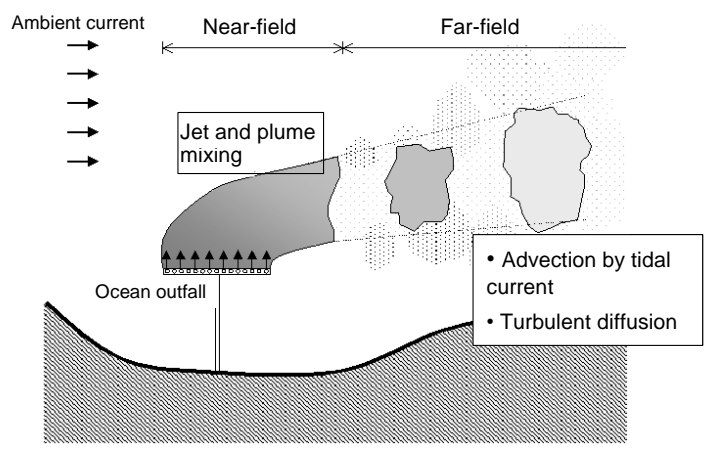

Figure 1: Mixing and transport of coastal outfall discharge [7]

By discharging the heated water through a large number of ports at a high velocity, the total area available for jet entrainment is increased, permitting the rapid dilution of the discharge water [8].

The power sources in Egypt are less than the power demands. As a result, more power plants and increasing the capacity of the existing ones are needed. Within the framework of increasing the power supply to meet the power demand Suez Power Plant will be built. The capacity of the plant is 650 Mega Watt. The plant will be located along the coast of Suez Gulf. Attaka Power Plant is located at $5 \mathrm{Km}$ west of the proposed Suez Plant.

Figure 2 shows the general layout of the location of Suez and Attaka Plants [9]. The Plant operation results in a plume that is characterized by high elevated temperatures.

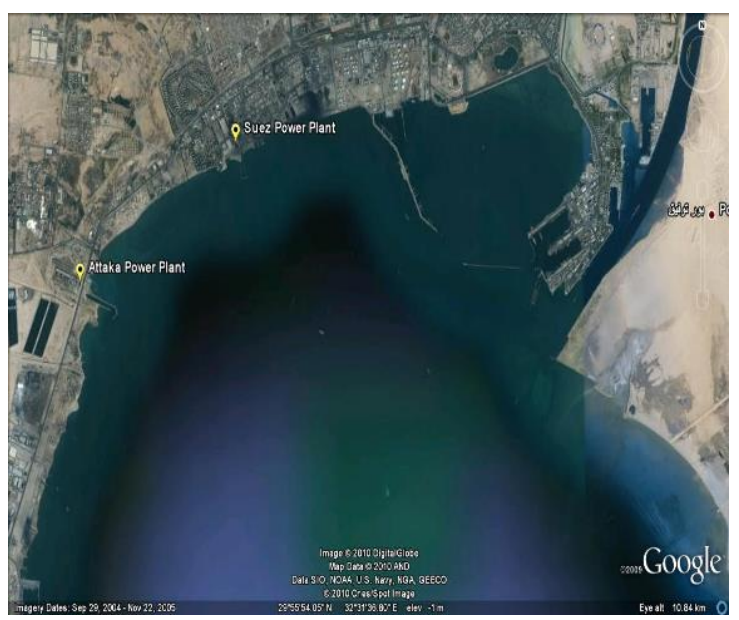

Figure 2: General layout of the Location of Suez and Attaka Plants

This research focused on the transport and advection of the plume on the recirculation of effluents at the plant intake and in the plant vicinity. In this research the impactwhich may occur from Attaka Plant on Suez Plant was considered. To achieve the aim of the research, the bathymetric, topographic and hydrometric data at the plant vicinity were carried out. These data are 
essential for developing and calibrating the models. A hydrodynamics numerical model was used to simulate the plume behavior.

\section{Description of Suze Power Plant}

The capacity of Suez Power Plant is $650 \mathrm{MW}$ power. The design inflow and outflow discharges of the proposed plant are $26 \mathrm{~m}^{3} / \mathrm{s}$. The design excess temperature above the ambient seawater at the outfall is $8^{\circ} \mathrm{C}$. Because of the limited area allocated to the plant, one option is to reclaim a part of the seawater in front of the plant to provide space for the plant facilities, as shown in Figure 3.

The existing intake will be replaced by a new one and will be located at the left side of the existing one while the proposed location of the outfall will be to the west of the existing intake as shown in Figure 3.

The plant will receive its cooling water from the Suez Gulf. The effluents will be discharged back through its outfall. The location of the intake and outfall of the cooling system should provide a high efficiency of the cooling system that can be fulfilled by eliminating the warm water from returning back to the plant intake.

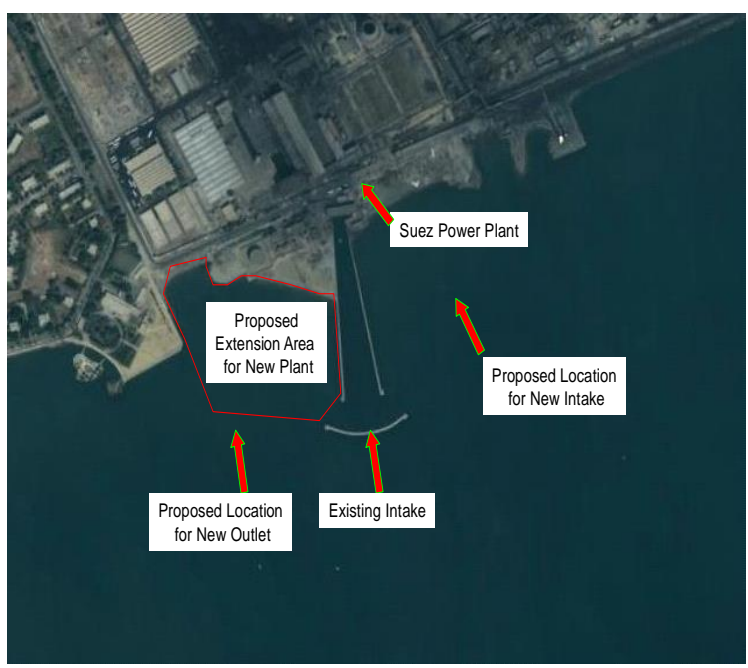

Figure 3: Proposed Location for the new intake and outlet of the Suez Power Plant

\section{Setup of the Hydrodynamic Model}

Two-dimensional (2D) hydrodynamic flow models were developed as follows:

Suez Gulf overall model: this model simulates the flow pattern in a larger area of the Suez Gulf waters. It is a coarse model and is used to provide the boundary conditions for the detailed model used to study the transport and dispersion of the plume around the proposed plant.

Detailed Suez Plant model: this model is nested in the Suez Gulf overall model. It has been used to provide quantitative results on tidal and wind-driven flows and recirculation of discharged excess temperature.

\subsection{Suez Gulf overall model}

In tidal models it is very useful to obtain the boundary conditions of the hydrodynamic models used in the research from a coarser model covers larger area of the seawater. In this research a coarser model covers a larger area of the Suez Gulf waters was developed and calibrated to provide the tidal forces for the detailed hydrodynamic model (Suez Power Plant model) which is used to study the recirculation and plume spreading. The bathymetric data of the Suez Gulf waters covers the area of inlet of Suez Canal till Al-Tur and RasGhareb cities were obtained from the Admiralty maps. Land boundaries reflecting the most recent site geometry have been compiled based on satellite images. The tidal constitutes of the water levels obtained at Al-Tur and Ras- Ghareb was used as a water level boundary condition of the model. The tidal constituents at Suez and Zafrana stations were used to calibrate the model. The tidal constituents were obtained from the Admiralty Tide Tables and are based on long-term tidal analysis of the measurements. Figure 4 shows the location of the tidal stations used in the model.

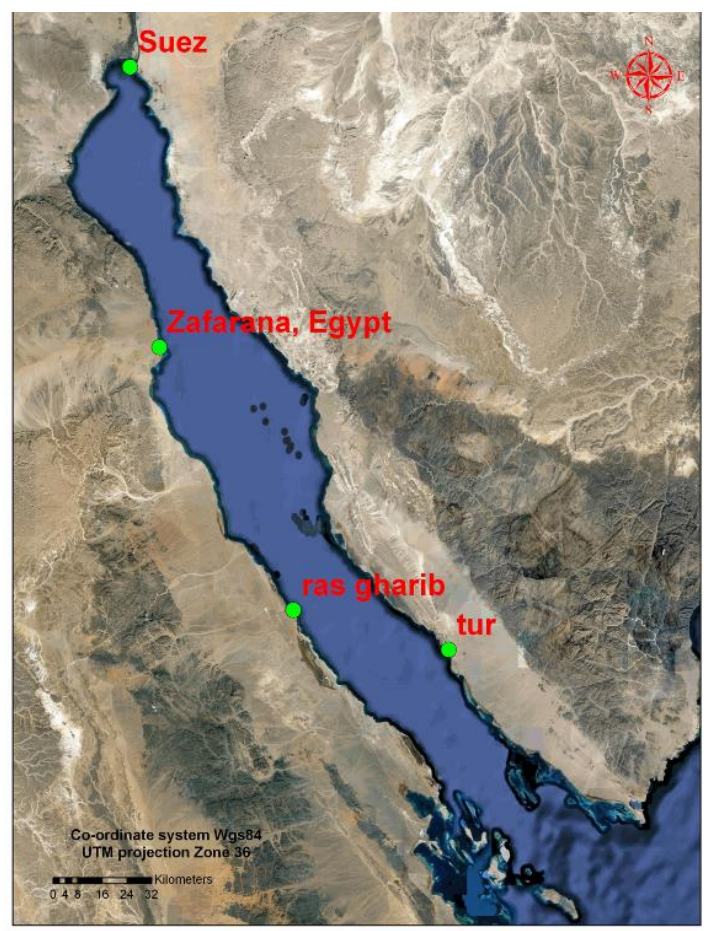

Figure 4: Location of the Tidal Station used in the Model Setup and Calibration

The computational model grid of the Suez Gulf overall model was developed based on a curvilinear grid technique. Figure 5 presents the computational model grid of the overall model.

The model has one boundary condition that extends from Al-Tur to Ras-Ghareb and is a water level boundary based on the astronomic tidal constituents at Al-Tur and Ras-Ghareb. Table 1 presents the tidal constituents used in the model. 


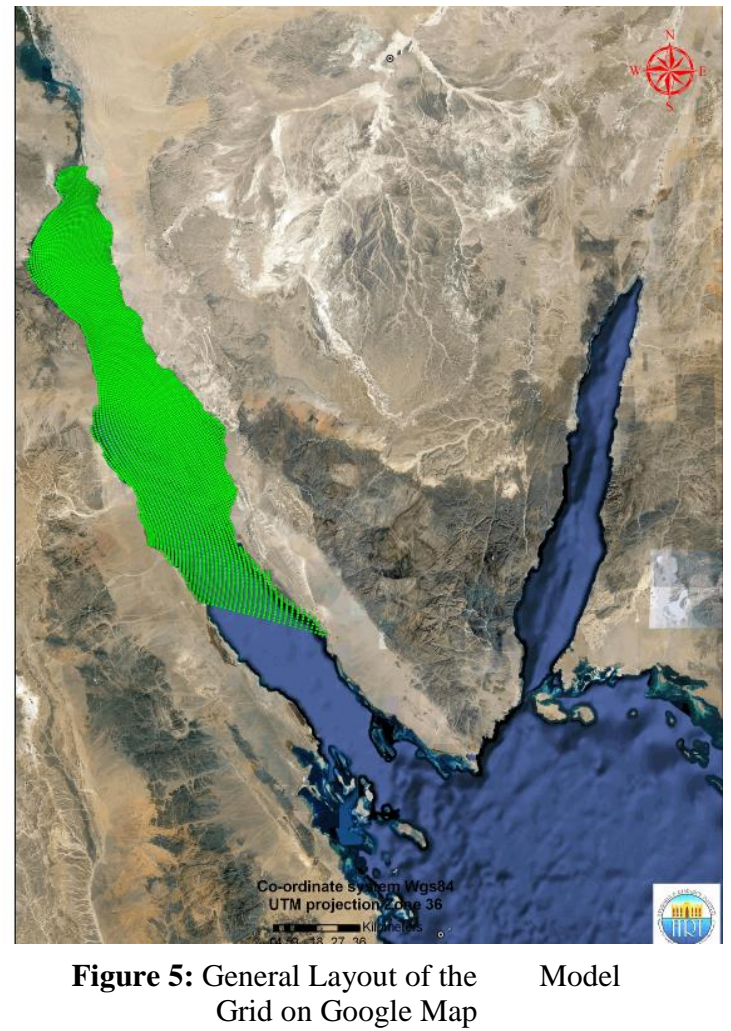

Table1: Tidal Constituents at Al-Tur and RasGhareb (sources: Admiralty Tide Tables)

\begin{tabular}{|c|c|c|c|c|}
\hline \multirow{2}{*}{ 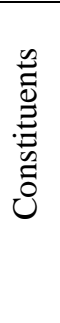 } & \multicolumn{2}{|c|}{ AL-Tur Station } & \multicolumn{2}{|c|}{ Ras-Ghareb Station } \\
\hline & 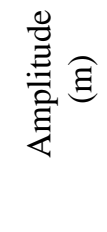 & 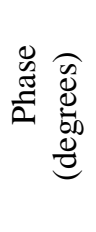 & 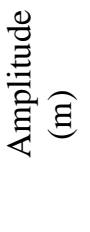 & 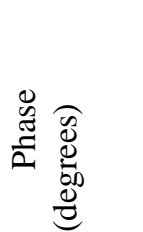 \\
\hline $\mathrm{M}_{2}$ & 0.08 & 263 & 0.18 & 332 \\
\hline $\mathrm{S}_{2}$ & 0.02 & 290 & 0.07 & 2 \\
\hline $\mathrm{N}_{2}$ & 0.03 & 242 & 0.06 & 310 \\
\hline $\mathrm{K}_{2}$ & 0.005 & 296 & 0.02 & 8 \\
\hline $\mathrm{K}_{1}$ & 0.04 & 197 & 0.03 & 190 \\
\hline $\mathrm{O}_{1}$ & 0.01 & 181 & 0.02 & 186 \\
\hline
\end{tabular}

The model was run for a period of 35 days and the time-series of the corresponding water levels at Suez and Zafrana stations were obtained from the model. The obtained water levels were analysed to get the amplitudes and phases of the tidal constituents. These tidal constituents were then compared with the available constituents at these stations from the Admiralty Tide Tables. Based on these results, the astronomic boundary conditions were tuned. An example of the model calibration is given in Table 2. It presents the tidal constituents as obtained from the final calibration of the model and from the Admiralty Tide Tables at Suez station.
Table 2: An example of the Model Calibration (Tidal Constituents at Suez Station)

\begin{tabular}{|c|c|c|c|c|}
\hline \multirow[b]{2}{*}{ Constituents } & \multicolumn{2}{|c|}{ Model Data } & \multicolumn{2}{|c|}{$\begin{array}{c}\text { Suez Station } \\
\text { Data }\end{array}$} \\
\hline & $\frac{\stackrel{0}{\Xi}}{\stackrel{\Xi}{\Xi}}$ & 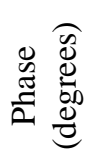 & 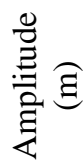 & 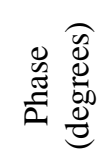 \\
\hline $\mathrm{M}_{2}$ & 0.55 & 331 & 0.56 & 336 \\
\hline $\mathrm{S}_{2}$ & 0.15 & 1 & 0.14 & 4 \\
\hline $\mathrm{N}_{2}$ & 0.19 & 308 & 0.18 & 313 \\
\hline $\mathrm{K}_{1}$ & 0.033 & 203 & 0.04 & 184 \\
\hline $\mathrm{O}_{1}$ & 0.021 & 185 & 0.01 & 198 \\
\hline
\end{tabular}

Table 2 Clarifies that the differences in the amplitudes and phase difference between the model and Admiralty Tide Tables are relatively small for the main tidal constituents (M2, S2 and N2). The relatively large difference in the phases of the small components (O1 and $\mathrm{K} 1$ ) has a minor influence on the tide water levels since their amplitudes are very small. Figure 6 shows the water levels obtained from the model and Admiralty Tide Tables at Suez Station.

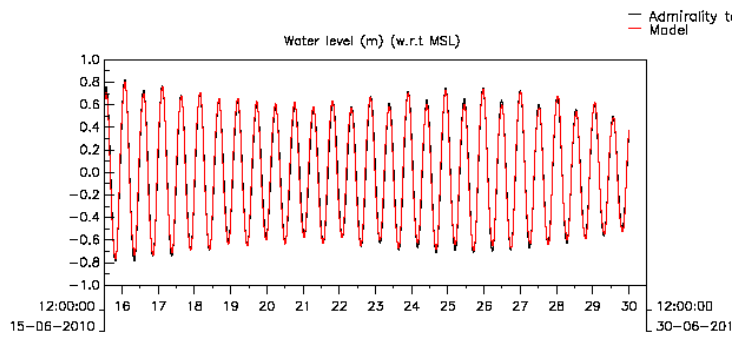

Figure 6: Water Level at Suez Station as Computed from the Model and From the Admiralty Tide Table

\subsection{Suez Plant Detailed Model Setup}

The Suez Plant hydrodynamic flow model was developed based on the present site geometry and recent hydrodynamic and bathymetric survey. The boundary conditions of the model were nested in the Suez Gulf overall model. Land boundaries reflecting the most recent site geometry have been compiled based on satellite images and the topographic survey.

Water levels and currents and temperature measurements have been made during the survey. The measurements at the vicinity of the proposed plant were used for model calibration. The 2D model grid was structured in order to focus the model resolution on the present site layout. This enables a good representation of the plant intake and outfall structures and of bathymetric features at the vicinity of these structures. The computational model grid is shown in Figure 7. The resolution of the model grid varies between $100 \mathrm{~m}$ at the model 
open boundaries to $25 \mathrm{~m}$, locally around the plant intake and outfall structures.

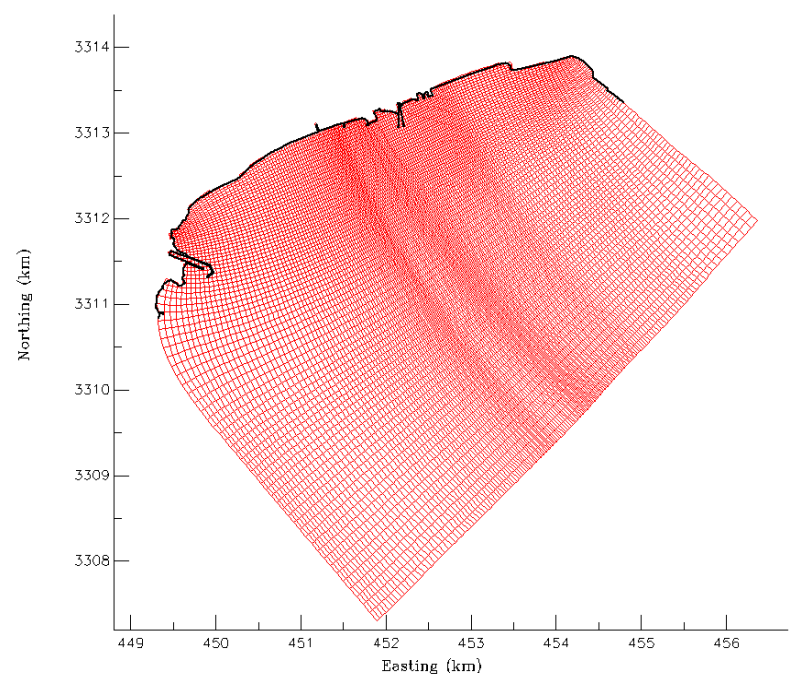

Figure 7: Computational Model Grid for Suez Plant Model

The tidal boundary forcing of the Suez Plant model was obtained by a step-wise nesting in the Suez Gulf overall model. This implies that, the overall model provides water level forcing to the Suez Plant detailed model and were converted to harmonic constituents by means of tidal analysis. The tidal dynamics in the Suez Power Plant model are subsequently driven by the prescription of tidal water level variations along the model boundaries with these harmonic constituents (a total of 6 constituents were applied). In addition, the tidal boundary forcing thus obtained for the Suez detailed model was optimized by model calibration with measured data.

Bed friction exerted on the moving water is included in the model schematization by means of a Chezy roughness coefficient of $65 \mathrm{~m}^{0.5} / \mathrm{s}$. The used value was obtained during model calibration. The computational time step applied for the hydrodynamic model is 0.15 minute. A spring-neap cycle (15 days) is subsequently used for model output.

\section{Calibration of the detailed model}

In the calibration phase, various model parameters may be adjusted within the limits of their uncertainties to achieve the best model results compared with the available measured data. Calibration is based on the comparison of model results with (pre-processed) measured data. For the present application, calibration focus on tidal water levels and currents. If the model is able to adequately represent these quantities, it is reasonable to assume that tidally driven transport is adequately resolved by the model dynamics. This is relevant to obtain an adequate representation of the effluent transport.
Water level measurements were available at three different locations in the modeled area, being $\mathrm{TG}_{1}$ (Suez station), $\mathrm{TG}_{2}$ (Attaka Station) and $\mathrm{TG}_{3}$ between the other two stations. From these measurements tidal components were derived by harmonic analysis. The tidal components were used for model calibration in the frequency domain. Current measurements were available at the locations where the water level measurements were carried out. These measurements were used in the model calibration. Figure 8 shows the location of these stations.

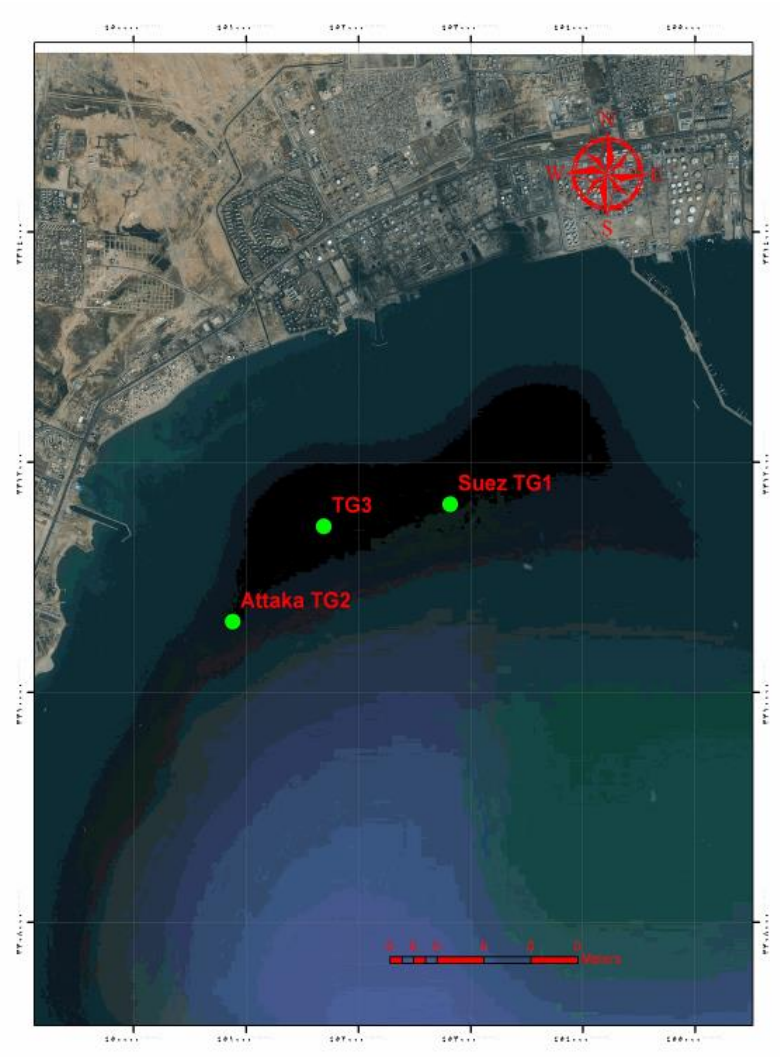

Figure8: Location of the Measuring Stations for Water Levels and Velocities

The model calibration focused on the correct model representation of amplitudes and phase lags for the most important tidal constituents in the area. By comparing the modeled and observed tidal amplitudes and phases, the tidal representation can be obtained. The comparison of tidal amplitudes and phases takes place in the frequency domain, where the ratio between modeled and observed amplitudes and the difference between modeled and observed phases are important measures to quantify the models tidal representation. As such, wind conditions and plant discharge will not affect this analysis. Based on the initial boundary forcing, of the Suez Plant detailed model additional corrections were applied to the tidal amplitudes and phases for some of the main tidal components $\left(\mathrm{K}_{1}\right.$, $\mathrm{P}_{1}, \mathrm{O}_{1}$ and $\mathrm{S}_{2}$ ). For the most important diurnal constituents $\left(\mathrm{O}_{1}, \mathrm{~K}_{1}\right)$ and semi-diurnal $\left(\mathrm{M}_{2}, \mathrm{~N}_{2}\right.$ and 
$\mathrm{S}_{2}$ ), the model performance at water level stations is obtained.

As summarized in Table 3, the mean amplitude ratios are within $5 \%$ of the ideal value. The absolute mean amplitude differences of the five constituents are $0.025 \mathrm{~m}$ or less. The absolute mean phase differences are below $5^{\circ}$ (approximately 20 minutes), for the diurnal constituents and lower than $16^{\circ}$ (approximately 30 minutes), for the semidiurnal constituents. These results are adequately representing the tidal water level variations and ensuing tidal currents in the project site.

Figure 9 shows the modeled and observed water levels at stations $\mathrm{TG}_{1}$ (Suez Station). It presents the results in spring-neap tidal cycles which present the most seasonal variation along the

Table 3: Model performance at water level stations used for tidal calibration

\begin{tabular}{|c|c|c|c|c|c|c|}
\hline & $\mathrm{O}_{1}$ & $\mathrm{~K}_{1}$ & $\mathrm{~K}_{2}$ & $\mathrm{~N}_{2}$ & $\mathrm{M}_{2}$ & $\mathrm{~S}_{2}$ \\
\hline Mean $\mathrm{H}_{\mathrm{c}}-\mathrm{H}_{\mathrm{o}}$ & -0.003 & -0.003 & 0.019 & -0.010 & -0.001 & -0.001 \\
\hline Abs. mean $\left|\mathrm{H}_{\mathrm{c}}-\mathrm{H}_{\mathrm{o}}\right|$ & 0.011 & 0.011 & 0.025 & 0.020 & 0.005 & 0.005 \\
\hline RMS err. $\mathrm{H}_{\mathrm{c}}-\mathrm{H}_{\mathrm{o}}$ & 0.016 & 0.016 & 0.028 & 0.023 & 0.007 & 0.006 \\
\hline Mean $\mathrm{H}_{\mathrm{c}} / \mathrm{H}_{\mathrm{o}}$ & 0.989 & 0.989 & 1.042 & 0.949 & 0.995 & 1.014 \\
\hline & & & & & & \\
\hline Mean $\mathrm{G}_{\mathrm{c}}-\mathrm{G}_{\mathrm{o}}$ & -0.797 & -0.797 & 2.044 & -1.127 & 2.317 & -8.423 \\
\hline Abs. mean $\left|\mathrm{G}_{\mathrm{c}}-\mathrm{G}_{\mathrm{o}}\right|$ & 4.281 & 4.281 & 3.020 & 3.006 & 3.629 & 15.895 \\
\hline RMS err. $\mathrm{G}_{\mathrm{c}}-\mathrm{G}_{\mathrm{o}}$ & 5.159 & 5.159 & 3.740 & 4.550 & 3.983 & 21.175 \\
\hline
\end{tabular}

$\mathrm{H}_{\mathrm{c}}$ indicates computed amplitude, $\mathrm{H}_{\mathrm{o}}$ indicates observed amplitude, $\mathrm{G}_{\mathrm{c}}$ indicates computed phase, $\mathrm{G}_{\mathrm{o}}$ indicates observed phase. $\mathrm{H}$ is specified in meters and $\mathrm{G}$ is specified in degrees.

Figure 10 show measured and computed current speed at Suez Station at mid water depth. It can be seen that flow velocities are generally low (approximately $0.1 \mathrm{~m} / \mathrm{s}$ at maximum). This is represented well by the model. It should be noted that currents are more sensitive to the local bathymetry than water levels. As such, the modeled currents will show effects of inaccuracies in measurements of (or changes to) the local bathymetry and the representation of the measured bathymetry on the coarser model grid. In addition to this, the accuracy of such low flow velocity measurements is lower than the higher velocities. The measured flow velocities are also subjected to the meteorological effects which is not the case in the model in which the meteorological effects are excluded. This explains the differences between the current speed between the model and prototype.

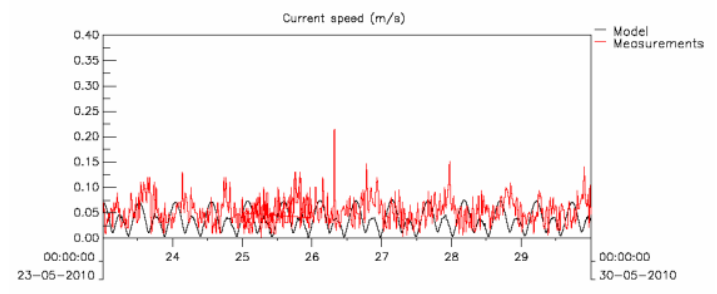

Figure 10: Computed and Measured Current Speed for Suez Stations (TG1)

\section{Model Scenarios and Results}

The first goal of the model scenarios is to assess the spreading and mixing of the discharge effluent (plume) and its impact on the surrounding areas. A second goal is to assess recirculation of temperature at the proposed Suez Plant intake. Eleven model scenarios were carried out as shown in Table 4.

Two options for the intakes/outfall layouts were investigated as follow:

- Option 1: considered the case of reclaiming a part of the sea to allow enough space for the plant facilities.

- Option 2: no reclamation will be carried out.

The simulations were carried out using ambient seawater in summer $\left(27^{\circ} \mathrm{C}\right)$. Each scenario is run for a spring-neap tidal cycle. For each scenario the design inflow/outflow discharges for the proposed Suez Power Plant and Attaka Power Plant is $26 \mathrm{~m} 3 / \mathrm{s}$ and $20 \mathrm{~m} 3 / \mathrm{s}$, respectively. The design excess temperature for the two plants at their outfall above the ambient seawater is $8^{\circ} \mathrm{C}$. 
Table 4 gives an overview of the model scenarios defined.

Table 4: Model Scenarios Simulation

\begin{tabular}{|c|c|c|c|c|}
\hline Modeling & Scenario ID & Wind Conditions & Reclamation & \\
\hline \multirow{8}{*}{$\begin{array}{l}2 \mathrm{D} \\
\text { Modeling }\end{array}$} & $\mathrm{S} 1$ & $\mathrm{NE}, 7 \mathrm{~m} / \mathrm{s}$ & \multirow{2}{*}{ Reclamation } & \multirow{4}{*}{$\begin{array}{l}\text { Intake is open channel } \\
\text { Outfall is onshore }\end{array}$} \\
\hline & $\mathrm{S} 2$ & $\mathrm{NW}, 7 \mathrm{~m} / \mathrm{s}$ & & \\
\hline & S3 & $\mathrm{NE}, 7 \mathrm{~m} / \mathrm{s}$ & \multirow{2}{*}{$\begin{array}{c}\text { No } \\
\text { Reclamation }\end{array}$} & \\
\hline & S4 & $\mathrm{NW}, 7 \mathrm{~m} / \mathrm{s}$ & & \\
\hline & S5 & $\mathrm{NE}, 7 \mathrm{~m} / \mathrm{s}$ & \multirow[t]{2}{*}{ Reclamation } & \multirow{4}{*}{$\begin{array}{l}\text { Intake is offshore pipeline } \\
\text { Outfall is onshore }\end{array}$} \\
\hline & S6 & $\mathrm{NW}, 7 \mathrm{~m} / \mathrm{s}$ & & \\
\hline & S7 & $\mathrm{NE}, 7 \mathrm{~m} / \mathrm{s}$ & \multirow{2}{*}{$\begin{array}{c}\text { No } \\
\text { Reclamation } \\
\end{array}$} & \\
\hline & S8 & $\mathrm{NW}, 7 \mathrm{~m} / \mathrm{s}$ & & \\
\hline \multirow{3}{*}{$\begin{array}{l}3 \mathrm{D} \\
\text { Modeling }\end{array}$} & S9 & \multirow{3}{*}{$\mathrm{NW}, 7 \mathrm{~m} / \mathrm{s}$} & Reclamation & \multirow[t]{2}{*}{$\begin{array}{l}\text { Intake is offshore pipeline } \\
\text { Outfall is onshore }\end{array}$} \\
\hline & $\mathrm{S} 10$ & & $\begin{array}{c}\text { No } \\
\text { Reclamation } \\
\end{array}$ & \\
\hline & $\mathrm{S} 11$ & & Reclamation & $\begin{array}{l}\text { Intake is open channel } \\
\text { Outfall is offshore pipeline }\end{array}$ \\
\hline
\end{tabular}

The model has to take into account representative conditions at the plant site. This implies that the model has to be run for representative tidal and wind conditions. As such, the tidal and wind forcing taken into account by the model must represent the predominant tidal and wind modes in order to represent their impact on plume dispersion.

At the Suez site, the tide is predominantly semi diurnal (i.e. having a period of nearly 12.5 hours). Interaction between the diurnal and semidiurnal tidal components will lead to a periodicity in tidal water levels over an approximately 15 day period, a so-called spring-neap cycle.

The model scenarios have to take into account the predominant wind modes in order to assess wind-driven spreading and mixing of the discharge plume. The wind directions and frequency of occurrence based on statistics of 7 years period (from 2003 to 2010) at Ras-Sudr Station located at the Suez Gulf near the project site was analysed. The following predominant wind modes are selected:

- A relatively strong uniform wind $(7 \mathrm{~m} / \mathrm{s})$ from north-westerly direction.

- A relatively strong uniform wind $(7 \mathrm{~m} / \mathrm{s})$ from north-easterly direction.

The north-westerly wind direction is the most dominant wind direction occurring for more than $70 \%$ of the time and that with increasing strength possibly induces wind driven transport of the plume toward the intake. This wind represents an adverse wind condition if one is interested in the possible risk of recirculation. The north-easterly wind direction with a maximum speed of $7 \mathrm{~m} / \mathrm{s}$ has been chosen to represent a wind direction that occurs around $10 \%$ of the time. A strong northeastern wind is regarded as favorable with regard to recirculation at the proposed Suez Plant because it enhances rapid dispersion and mixing of the effluent in easterly direction. The north-westerly and north-easterly winds are subsequently imposed for a period of 15 days during spring-neap-tide.

6. Model Results

\section{1 $S_{1}$ and $S_{2}$ Scenarios}

$S_{1}$ and $S_{2}$ scenarios took the reclamation area into consideration, the intake of the plant is an open channel and the outfall is onshore as shown in Figure 11. In these scenarios a NE $7 \mathrm{~m} / \mathrm{s}$ and a NW $7 \mathrm{~m} / \mathrm{s}$ wind conditions are introduced respectively.

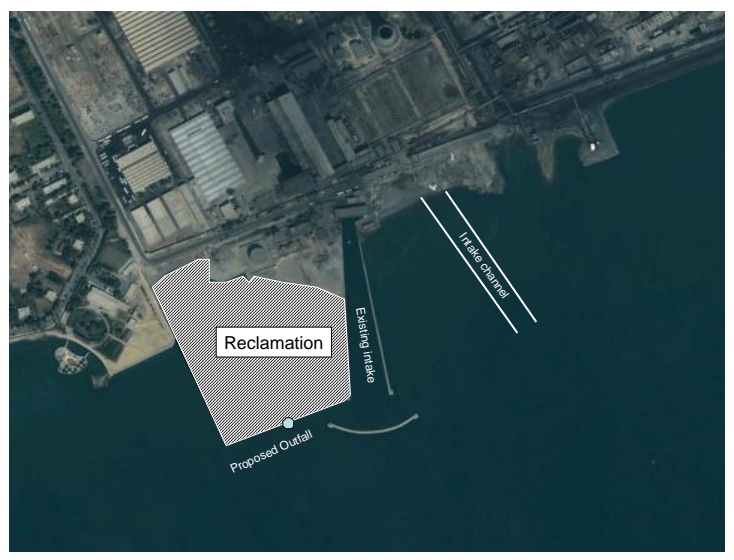

Figure 11: Layout of the Intake/Outfall System considering Reclamation Area

Figure12 show the temperature distribution around the proposed Suez Plant and the existing Attaka Plant at the characteristic moments of ebb conditions (close to the low water level). The ebb condition is the worst moment along the tidal cycle because the dilution and water mixing is relatively low. This figure presents the results of Scenario S2 in which the NW $7 \mathrm{~m} / \mathrm{s}$ wind condition is 
introduced in the model. The Figure shows that there will be a recirculation at the new intake of about $2.5^{\circ} \mathrm{C}$, which will affect the plant efficiency. The reason is that NW wind transports the plume from Attaka to Suez Plant where this plume merges with the plume from Suez Plant. The plume concentration is transported to the intake of Suez Plant leading to the recirculation.
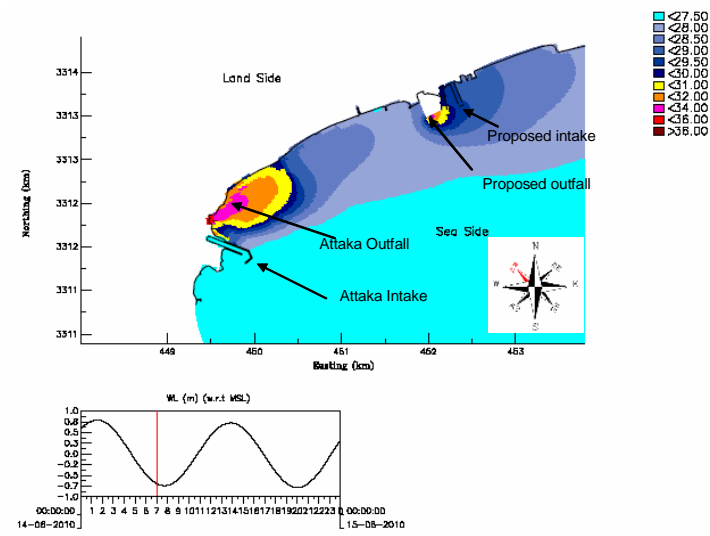

Figure 12: Temperature Distribution for Scenario $S_{2}$, Maximum Ebb Flow

While the results of Scenario S1 show that there is no recirculation of the effluents at the proposed intake structure of Suez Plant in case of $\mathrm{NE}$ wind condition. It is observed that the plume from Attaka Plant merges with that from Suez Plant leading to temperature concentration at the vicinity of both plants. However, the intake of the proposed plant will not be affected by the thermal plumes. The excess temperature above the ambient seawater at the vicinity of the Suez Plant is more than $2^{\circ} \mathrm{C}$.

\section{2 $S_{3}$ and $S_{4}$ Scenarios}

$\mathrm{S}_{3}$ and $\mathrm{S}_{4}$ scenarios were carried out with no reclamation area in the seawater, see figure 13 . The outfall and the intake of the Suez Plant are the same as in Scenarios $S_{1}$ and $S_{2}$ Wind conditions NE 7 $\mathrm{m} / \mathrm{s}$ and NW $7 \mathrm{~m} / \mathrm{s}$ are introduced in Scenarios $S_{3}$ and $\mathrm{S}_{4}$, respectively. Figure 14 shows the temperature distribution around the proposed Suez Plant and the existing Attaka Plant for $\mathrm{S}_{4}$ scenario during the characteristic moments of flood and ebb flows.

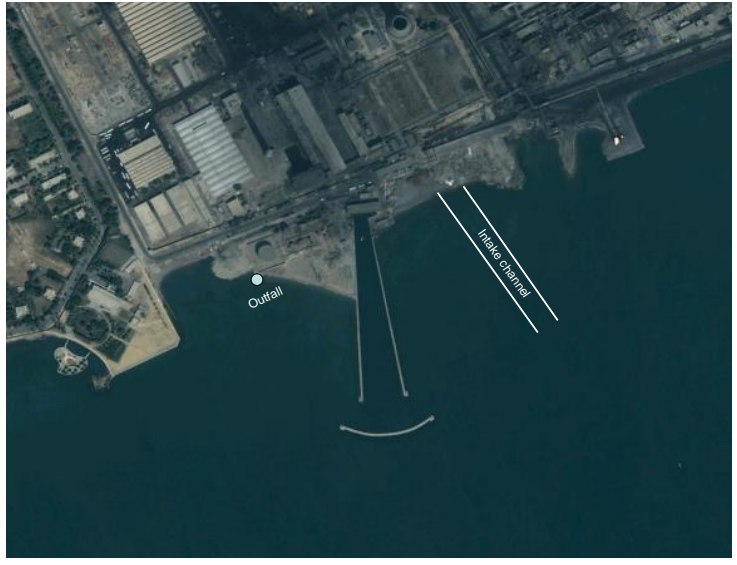

Figure 13: Layout of the Intake/Outfall System without Reclamation Area

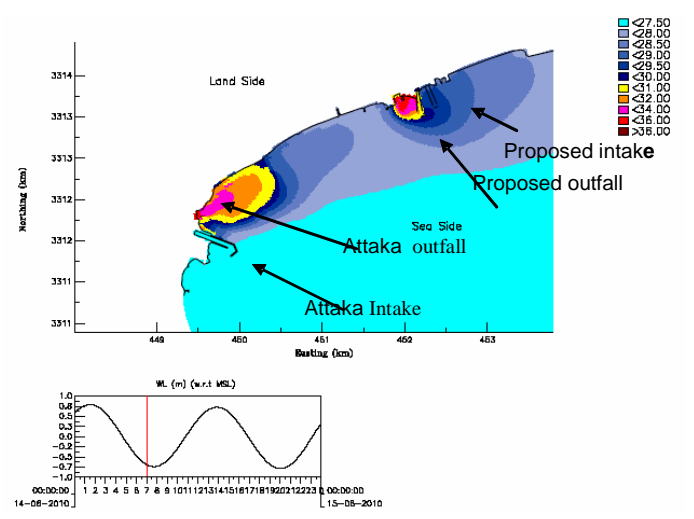

Figure 14: Temperature Distribution for Scenario $S_{4}$, Maximum Ebb Flow

The model results for Scenarios $S_{3}$ and $S_{4}$ gave almost the same results as in $S_{1}$ and $S_{2}$ Scenarios from the recirculation point of view at the proposed intake. Only the shape of the plume differs to some extent. This means that the reclamation area does not affect the recirculation of the effluents at the intake of the proposed plant. The reclamation area has a small effect on the plume spreading compared to the situation without reclamation. Figure 14 shows the temperature distribution at the intake of the proposed plant in case of no reclamation and under the NW $7 \mathrm{~m} / \mathrm{s}$ wind condition $\left(\right.$ Scenario $\mathrm{S}_{4}$ ). It also shows that the average recirculation at the intake during spring-neap tidal cycle is about $1.75^{\circ} \mathrm{C}$ while its maximum value is about $2.5^{\circ} \mathrm{C}$.

6.3 Improving the Recirculation at the intake of Suez Plant $\left(S_{5}\right.$ to $\left.S_{8}\right)$

To minimize the recirculation at the intake of the proposed Suez Plant and to avoid the area of the plume merge of both Suez and Attaka Power Plants is to make the intake as offshore a pipe-line extends far offshore. Different model scenarios were made for different lengths of offshore intake pipeline to 
optimize the length of the offshore pipeline to get the shortest length with minimum recirculation. The model scenarios showed that a length of about $1.5 \mathrm{~km}$ offshore intake pipeline gives a good result. The outfall will be onshore (same location as in Scenarios $S_{1}$ to $S_{4}$ ). Figure 15 shows a general layout of scenarios $S_{5}$ and $S_{6}$.

Figure 16 shows the recirculation at the inlet of the proposed intake pipeline system of Suez Plant for Scenario S6 at the moment of ebb flow for $7 \mathrm{~m} / \mathrm{s}$ NW wind with reclamation. The figure shows that the maximum recirculation during spring-neap tidal cycle is about $0.3^{\circ} \mathrm{C}$.

The model results for scenarios $S_{6}$ to $S_{8}$ prove that the proposed intake pipeline system which extends about $1.5 \mathrm{~km}$ offshore direction will improve the results compared to the intake channel proposed in Scenarios $S_{1}$ to $S_{4}$. The recirculation at the intake of the Suez Plant will be reduced to less than $0.5^{\circ} \mathrm{C}$. The effect of the reclamation area on the recirculation and the temperature at the plant vicinity is very small as can be seen through comparing the results of Scenarios $S_{5}$ and $S_{6}$ with scenarios $S_{7}$ and $S_{8}$.

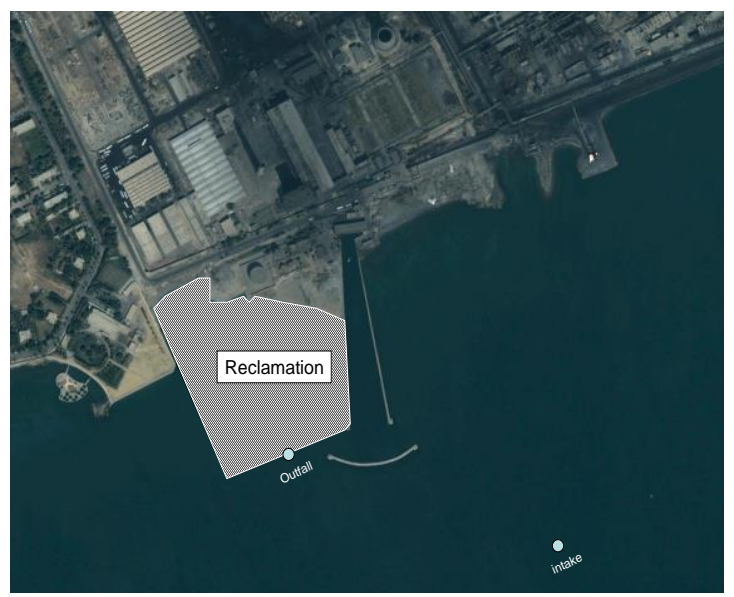

Figure 15: Layout of the Intake/Outfall System for $S_{5}$ and $\mathrm{S}_{6}$ Scenarios

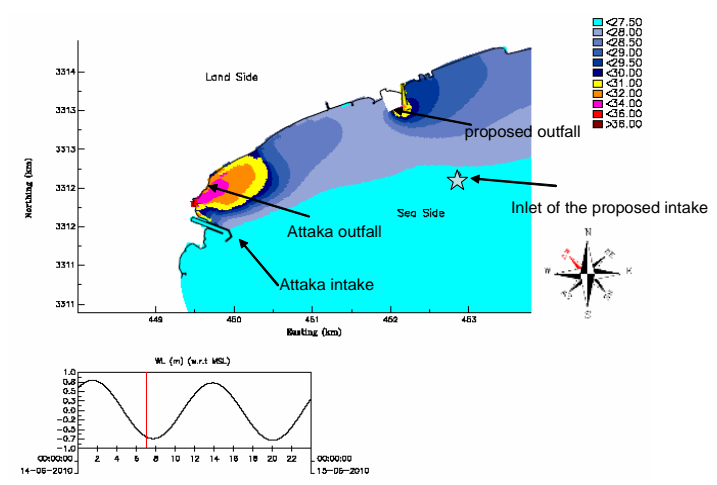

Figure 16: Temperature Distribution for Scenario S6, Maximum Ebb Flow

\subsection{Three Dimensional Modeling}

The Two dimension (2D) modeling was used to test the proposed scenarios and to get the optimum alternative which minimizes the recirculation of the effluents from the plant outfall to its intake. The results of the $2 \mathrm{D}$ modeling show that using a pipeline intake of about $1.5 \mathrm{~km}$ long improves the results of the recirculation (S5 to S8). The results also show that reclamation will not have a remarkable effect on the recirculation and the temperature distribution in the plant vicinity. The simulations show that the NW wind of $7 \mathrm{~m} / \mathrm{s}$ gives the highest recirculation at the Suez Plant intake. Based on the results of the 2D simulations, 3D simulations were carried out for scenarios S9 to S11 as described in Table 4. The depth-averaged 2D models were extended to $3 \mathrm{D}$ models with 4 layers along the water column. In the Scenarios S9 to $\mathrm{S} 11$ the water column is divided into 4 layers. Each layer represents $25 \%$ of the water column. K$€$ turbulence closure model was used in the 3D simulations. In Scenarios S9 and S10 the intake pipeline system is in the bottom layer (layer 4). The outfall discharges its water at full depth along the water column. The results of the three scenarios S9 to S11 are shown for the top and bottom layers. The temperature distribution around the plant structures is presented at the characteristic moment of the ebb flow (close to the low water) because it is the critical moment from the recirculation point of view. The simulations were carried out with $7 \mathrm{~m} / \mathrm{s} \mathrm{NW}$ wind because it is the unfavorable wind from the recirculation point of view for the Suez Plant. The 3D model results will be presented as follow:

\section{Scenario $\mathbf{S}_{9}$}

In $S_{\text {Scenario }} S_{9}$ the intake of the proposed $\mathrm{Suez}_{\mathrm{a}}$ Plant is offshore pipeline extends about $1.5 \mathrm{~km}$ offshore direction. The pipeline is accommodated in layer number 4 in the 3D model (bottom layer). The outfall is onshore discharging its water over the 4 layers of the model. The wind is $7 \mathrm{~m} / \mathrm{s} \mathrm{NW}$. Figures 17 and 18 show the concentration of the plume and its spreading in top and bottom layers, respectively. It can be seen that the concentration and plume spreading in the top layer is more than that in the bottom layer because of the higher temperature of the plume than the ambient water condition. 

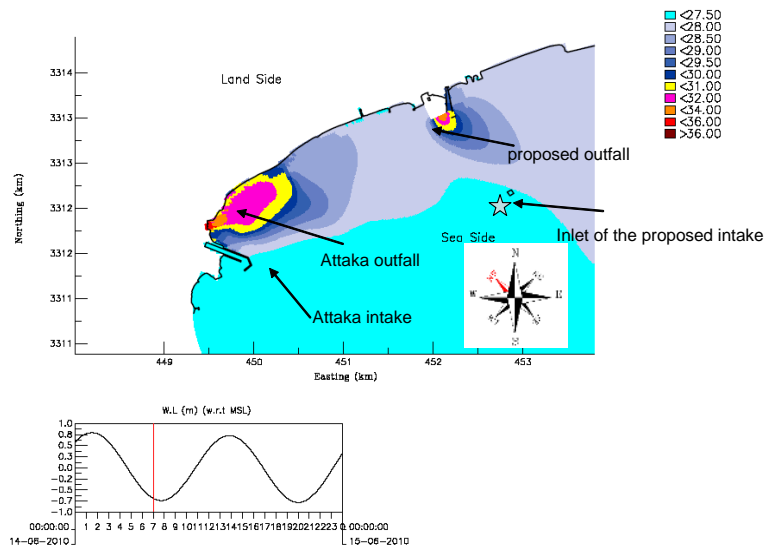

Figure 17: Temperature Distribution for Scenario $S_{9}$, Top Layer, Maximum Ebb Flow

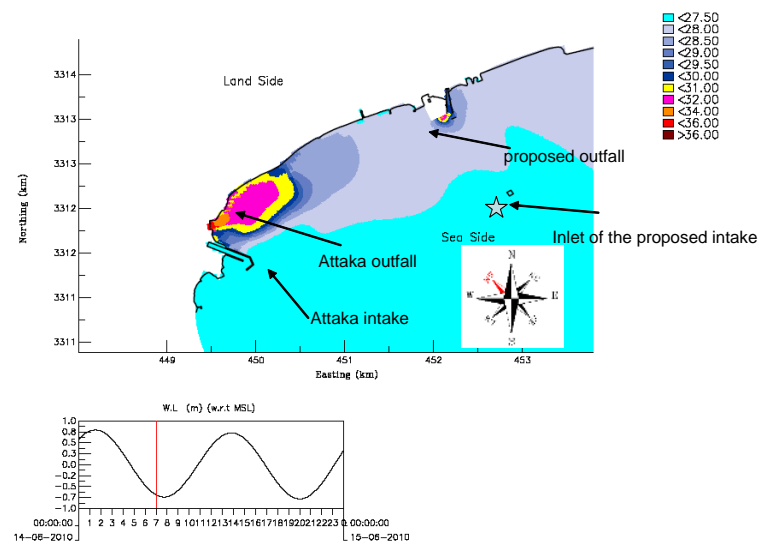

Figure 18: Temperature Distribution for Scenario $S_{9}$, Bottom Layer, Maximum Ebb Flow Scenario $S_{11}$

In this scenario, the intake of the proposed plant is an open channel as in Scenarios S1 to S4, but the outfall is simulated as a pipeline with a diffuser and extends about $1.5 \mathrm{~km}$ from the shoreline. Figures 19 and 20 show the temperature distribution in the top and bottom layers, respectively. These Figures show that the offshore outfall pipeline system does not provide a good improvement regarding the recirculation at the intake of the proposed plant. On the other hand, discharging hot water offshore may affect the marine life and corals, if they are present.
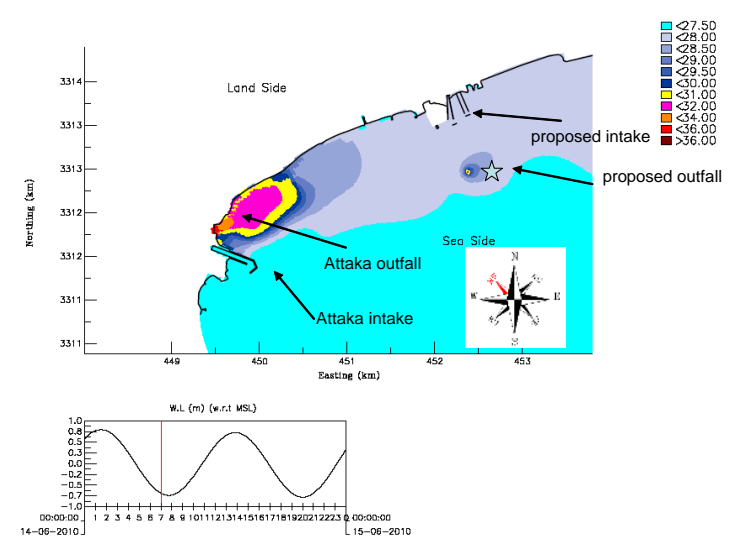

Figure 19: Temperature Distribution for Scenario $S_{11}$, Top Layer, Maximum Ebb Flow
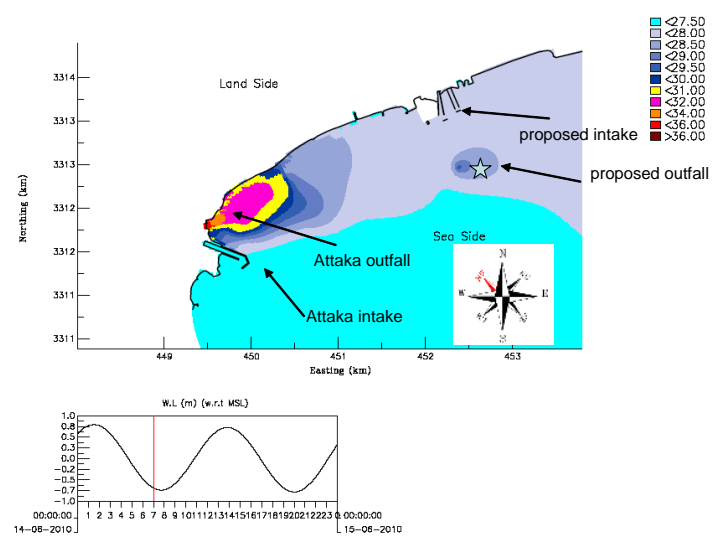

Figure 20: Temperature Distribution for Scenario $S_{11}$, Bottom Layer, Maximum ebb Flow

\section{Conclusions}

With the aim of investigating the recirculation of the effluents from the outfall to the intake of the proposed Suez Power Plant and the elevated temperature around the plant, $2 \mathrm{D}$ and $3 \mathrm{D}$ dimensional numerical hydrodynamic flow models were carried out. Two options were tested in the hydrodynamic models as follows:

- Option 1: Reclamation of the seawater to allow space for the plant facilities

- Option 2: No reclamation

Wind conditions $7 \mathrm{~m} / \mathrm{s} \mathrm{NE}$ and $7 \mathrm{~m} / \mathrm{s} \mathrm{NW}$ were introduced to the models. In the 2D model, four scenarios (S1 to S4) were tested. It was found from the simulations results that $\mathrm{NW}$ wind of $7 \mathrm{~m} / \mathrm{s}$ causes the plume of the existing Attaka plant to merge with the plume of the proposed Suez Plant. As a consequence, there will be a recirculation at the intake of the proposed plant of about $2^{\circ} \mathrm{C}$ on average and $3^{\circ} \mathrm{C}$ at the maximum.

The reclamation of the seawater to provide more enough space for the plant facilities hardly affects the recirculation of the effluents at the intake of the proposed plant compared with the situation with no reclamation.

The model results show that the excess temperature around the plant is less than $10^{\circ} \mathrm{C}$ in all scenarios

With the aim of minimizing the recirculation at the intake of the proposed Suez Plant, it was proposed to change the proposed intake structure of the Suez Plant from open channel to a pipeline that extends to about $1.5 \mathrm{~km}$ to the offshore direction. Scenarios S5 to S8 tested the proposed intake structure. The results showed that the recirculation 
at the inlet of the proposed intake will be reduced considerably. The maximum recirculation in the bottom layer i.e. close to the bed will be about $0.3^{\circ} \mathrm{C}$.

After the 2D model simulations, it has been proved that the pipeline intake of the proposed plant can reduce the recirculation. It was tested on a $3 \mathrm{D}$ model to show the stratification of the temperature along the water column due to the plume effect. The model consists of 4 layers along the water column. Each layer simulates $25 \%$ of the water column. These simulations were carried out at the worst case of the wind conditions of $7 \mathrm{~m} / \mathrm{s}$ NW. This wind causes recirculation at the proposed open channel intake (S2 and $\mathrm{S} 4)$. The recirculation achieves peak values of about $2.5^{\circ} \mathrm{C}$.

The 3D model simulations show that the temperature due to plume spreading in the top layer is higher than the bottom layer. This will reduce the recirculation of the effluents at the inlet of the offshore pipelines system mounted on the seabed. In this case, the recirculation will be about $0.5^{\circ} \mathrm{C}$ maximum in the worst case of $7 \mathrm{~m} / \mathrm{s} \mathrm{NW}$ wind.

The offshore outfall pipeline system will not provide a good improvement regarding the recirculation at the intake of the proposed plant. On the other hand, discharging hot water offshore may affect the marine life and corals, if they are present.

\section{Recommendations}

Based on the numerical model results, it can be recommended that:

Either onshore or open channel seawater intake with short length of the proposed Suez Plant is not recommended because the recirculation of effluents at the intake will be relatively high.

One option which can be recommended is to use offshore pipeline intake system with a length of about $1.5 \mathrm{~km}$ to avoid the high recirculation at the intake.

The results of the numerical models should be confirmed by a physical scale model.

If the reclamation of the seawater is required to allow for more area for the plant facilities it is necessary to take a permit from the Shore Protection Authority (SPA).

It is recommended to carryout shoreline morphological model to investigate the impact of the intake/outfall structures on the shoreline changes.

\section{References}

[1] Alesheikh, A. A.; Ghorbanali, S. A.; Nouri, N., (2007), "Coastline change detection using remote sensing" Int. J. Environ. Sci. Tech., 4 (1), 61-66.

[2]Karuppanapandian,T.;Karuppudurai,T.;Kumarag uru, A. K., (2007), "A preliminary study on the environmental condition of the coral reef habitat", Int. J. Environ. Sci. Tech., 4 (3), 371-378.

[3] Nouri, J.; Karbassi. A. R.; Mirkia,S., (2008), "Environmental management of coastal regions in the Caspian Sea" ,Int. J. Environ. Sci. Tech., 5 (1), 43-52.

[4] Cetin, M., (2009), "A satellite based assessment of the impact of urban expansion around a lagoon", Int. J. Environ. Sci. Tech., 6 (4), 579-590.

[5] Falconer, R. (1992), "Flow and water quality modelling in coastal and inland waters", J. Hydraul. Res., 30 (3), 437-452.

[6] Elsayed, E. M.,(1981), "A thermal-hydraulic model investigation of submerged multi-port diffuser for offshore discharge of condensercooling water", Flow systems Laboratory, Ontario Hydro, Toronto, Ontario, Report No. 81499.

[7] K.W. CHOI and JOSEPH H.W. LEE, 2005, "A new approach to effluent plume modeling in the intermediate field", XXXI IAHR CONGRESS, Seoul, Korea.

[8] Kim, D. G.; Soe, I. W., 2000, "Modeling the Mixing of Heated water discharge from a submerged multiport diffuser". J. Hydro. Res., 38 (4), 259-269.

[9] Hydraulics Research Institute, 2010, "Hydrothermal Modelling Study Suez Power" Final Report. 